\title{
The treatment of displaced supracondylar fractures of the humerus in children
}

\author{
A comparison of three methods
}

\author{
M. Ababneh, A. Shannak, S. Agabi, S. Hadidi \\ Department of Orthopaedic Surgery, Faculty of Medicine, University of Jordan, Amman, Jordan
}

Accepted: 9 January 1998

\begin{abstract}
Summary. This retrospective study compares the long-term results of the treatment of 135 children with displaced extension-type supracondylar fractures of the humerus using 3 different methods. Closed reduction and percutaneous fixation was superior with excellent and good results in $87 \%$ and had the lowest incidence of poor results (8\%). Open reduction and wire fixation, and closed reduction with a plaster cast gave excellent and good results in $74 \%$ and $60 \%$ respectively. Closed reduction and wire fixation is recommended as the treatment for grades II and III supracondylar fractures.
\end{abstract}

Résumé. Il s'agit d'une étude rétrospective comparant les résultats à long terme de 135 enfants atteints d'une fracture supracondylienne de l'humerus (FSH) type "extension" traitée par trois différentes méthodes. La réduction à foyer fermé avec fixation percutanée a été supérieure aux deux autres méthodes puisqu'elle a donné le plus haut taux d'excellents et de bons résultats (87\%) et le plus bas taux de mauvais résultats (80\%) ce selon les critéres de Flynn et al.. La réduction à foyer ouvert avec fixation par broche et à foyer fermé et plâtrage venaient en deuxième lieu concernant l'incidence d'excellents et bons résultats et ils étaient respectivemet de l'ordre de $74 \%$ et $60 \%$. Se basant sur les résultats à long terme et le taux de complications, il s'avère que la réduction à foyer fermé avec fixation par broche est à recommander pour le traitement des stades II et III du "FSH".

Reprint requests to: $\mathrm{M}$. Ababneh, University of Jordan, PO Box 13050, Amman, Jordan

\section{Introduction}

Displaced supracondylar fractures (SCF) of the elbow may show instability following closed reduction unless the elbow is immobilised in a flexion position. This may compromise circulation and be followed by the development of a varus deformity which has a reported incidence of from $9 \%$ to $57 \%[1,13]$.

The dangers and difficulties of closed reduction, with or without the application of a cast, include the risk of circulatory embarrassment of the forearm and hand, the tendency to recurrence of displacement, and the increased incidence of cubitus varus deformity [4, $6,12]$. Traction, which has been shown to give satisfactory results, is time-consuming and requires intensive nursing care $[7,14]$. Closed reduction with percutaneous wire fixation has excellent results with negligible complications $[2,5,10]$. Open reduction and wire fixation has been advised for cases associated with neurovascular injuries and for fractures which are not satisfactorily reduced $[7,12]$.

This retrospective study compares the long-term results of three methods of treatment.

\section{Patients and methods}

Two hundred and five children with displaced extension-type SCFs were treated at the Jordan University Hospital between January 1980 and December 1989. Complete follow-up data were available for only 135 patients. We found that the Liang classification was a simple and practical method of grading these fractures [3]: $40 \%$ of our cases were in grade II and $60 \%$ in grade III. The mean of the age of the patients was 6 years (range 2 to 12 years).

Associated injuries occurred in 34 patients. Circulatory insufficiency was evident by an impalpable radial pulse in 16 children. There were vascular problems in 2 others who had cold pale hands, an impalpable radial pulse and inadequate collateral circulation. The brachial artery was explored in 
Table 1. Methods of treatment

\begin{tabular}{lll}
\hline Method & \multicolumn{2}{l}{ Fracture type } \\
\cline { 2 - 3 } & $\begin{array}{l}\text { Grade II } \\
\text { no. }\end{array}$ & $\begin{array}{l}\text { Grade III } \\
\text { no. }\end{array}$ \\
\hline $\begin{array}{l}\text { Closed reduction and cast application } \\
(n=45)\end{array}$ & 22 & 23 \\
$\begin{array}{l}\text { Closed reduction and percutaneous wire fixation } \\
(n=37)\end{array}$ & 18 & 19 \\
$\begin{array}{l}\text { Open reduction and wire fixation } \\
(n=53)\end{array}$ & 14 & 39 \\
\begin{tabular}{l} 
Total \\
\hline
\end{tabular} & -54 & 81 \\
\hline
\end{tabular}

these 2 patients and found to be interposed between the fracture fragments. Ipsilateral fractures were present in 8 patients involving both bones in 5 and the distal radius in 3 . Nerve injuries were seen in 8 patients affecting the radial nerve in 4 , the median in 3 and the ulnar in one patient. All of the nerve injuries were the result of the fracture itself with one exception. The ulnar nerve injury was iatrogenic.

The 3 different methods of treatment are summarized in Table 1.

(1) Closed reduction under general anaesthesia and the application of a plaster cast was used initially in 61 children, the elbow being maintained in a posterior splint at $90^{\circ}$ to $110^{\circ}$ degree of flexion. Rotation of the forearm in plaster was not considered in all of the cases. Recurrence of displacement or vascular complications occurred in 16 patients and a further closed or open reduction and wire fixation was carried out. The posterior splint was completed to a cylindrical cast in the remaining 45 patients when the fracture was in an acceptable postion radiologically; it was removed 4 weeks later and active mobilisation was started.

(2) Closed reduction and percutaneous wire fixation was performed in 37 patients, and was the initial method in 30; in 7 it was carried out after reduction and cast application had failed. General anaesthesia and direct imaging were used. The position was maintained with crossed wires. Posterior plaster splints were applied at about $70^{\circ}$ of flexion. The splints and wires were removed after 4 weeks.
(3) Open reduction and wire fixation was used in 53 patients and was the initial management in 44 of them; in 7 cases it was used after failed closed reduction, and also in the 2 patients who had immediate exploration of the brachial artery. The posterior approach was used in 25 patients, the lateral in 8 , and the medial in 4 ; in the remaining 16 , reduction was not satisfactory through a lateral approach, and an additional short medial incision was used. Fixation was achieved by crossed wires regardless of the surgical approach.

\section{Evaluation}

Both elbows of all the patients were examined for movement, measurement of the carrying angle with a goniometer and examination of the neurological status. The criteria of Flynn et al. were used [1] and loss of movement and changes in carrying angle were recorded in $5^{\circ}$ intervals. The lesser of the two measurements was adopted as the overall rating of the affected elbow. Any child with a varus deformity was rated as poor.

\section{Results}

The results obtained with the 3 different methods of treatment are shown in Table 2. Closed reduction
Table 2. Results of each method of treatment using the criteria of Flynn et al.

Table 3. Analysis of poor results

\begin{tabular}{lllll}
\hline Method of treatment & \multicolumn{2}{l}{ Results } & & \\
\cline { 2 - 5 } & Excellent & Good & Fair & Poor \\
\hline $\begin{array}{c}\text { Closed reduction and application of cast } \\
(n=45)\end{array}$ & $36 \%$ & $24 \%$ & $9 \%$ & $31 \%$ \\
$\begin{array}{c}\text { Closed reduction and percutaneous wire fixation } \\
\quad(n=37)\end{array}$ & $76 \%$ & $11 \%$ & $5 \%$ & $8 \%$ \\
$\begin{array}{c}\text { Open reduction and wire fixation } \\
(n=53)\end{array}$ & $55 \%$ & $19 \%$ & $4 \%$ & $22 \%$ \\
\hline
\end{tabular}

\begin{tabular}{llllr}
\hline Method of treatment & $\begin{array}{l}\text { Loss of } \\
\text { motion }\end{array}$ & $\begin{array}{l}\text { Cubitus } \\
\text { varus }\end{array}$ & $\begin{array}{l}\text { Cubitus } \\
\text { vulgus }\end{array}$ & Total \\
\hline Closed reduction and application of cast & 5 & 9 & - & 14 \\
Closed reduction and percutaneous pinning & - & 2 & 1 & 3 \\
Open reduction and wire fixation & 5 & 7 & - & 12 \\
\hline
\end{tabular}


with percutaneous wire fixation achieved better results than the other two methods. Six of the ipsilateral fractures were treated by closed reduction and cast application, and 2 by closed pinning.

All fractures healed without complications. The circulation was adequate in 16 out of 18 patients after open or closed reduction and wire fixation, followed by positioning the elbow in a posterior splint at less than $90^{\circ}$ flexion, the radial pulse returning within $8 \mathrm{~h}$ after operation. In 2 patients, the radial pulse returned after 10 and 14 days respectively; recovery was complete without any ischaemic damage. Every neurological complication recovered completely within 6 months.

Table 3 shows an analysis of the poor results. Fourteen of the 45 patients treated by closed reduction and cast application had poor results, 9 with a decrease in the carrying angle which ranged from 5 to 26 degrees; 5 had loss of motion which ranged from $18^{\circ}$ to $32^{\circ}$ of flexion in 3 and from 15 to $40^{\circ}$ of flexion in 2. Cubitus varus of an average of $8.4^{\circ}$ developed in 7 patients treated by open reduction. Five patients in this group had an average loss of $23^{\circ}$ flexion in $3,32^{\circ}$ of extension in one, and the other had a stiff elbow. The 3 poor results after closed pinning were due to a decrease in the carrying angle of $16^{\circ}$ and $19^{\circ}$ in 2 and an increase in the angle from $+4^{\circ}$ to $21^{\circ}$ with an average loss of movement of $6.8^{\circ}$ in the third.

\section{Discussion}

The main objectives of treatment of displaced SCFs in children are the prevention of Volkmann's contracture, the avoidance of deformities, and restoration of normal function [8].

The incidence of associated injuries in this study was comparable to those reported by others $[4,13]$. The time required for the return of an absent radial pulse after reduction and stable positioning of the elbow was also comparable [11]. Exploration of the brachial artery is justified in cases where signs of ischaemia persist after reduction since functional disturbances may follow insignificant levels of ischaemia, as in the anterior tribial compartment syndrome [13].

The best results were achieved by closed reduction and wire fixation as judged by the highest incidence of excellent results and the lowest incidence of poor results; similar observations have been made by others $[1,2,5,7]$. Three patients had poor results with varus and valgus deformities because of an unsatisfactory initial reduction. Rotation of the distal fragment predisposes to such deformities [1, 13].

The high incidence of poor results with closed reduction and cast application has been reported by others $[7,9]$. The relatively large number of poor results after open reduction and wire fixation is be- lieved to be due to the high proportion (74\%) of severely displaced grade III fractures in this group, and to the delay in initiating treatment because of the late arrival at the hospital of up to 10 days. Open reduction through short medial and lateral incisions had the best outcome.

The best method of treatment is early closed reduction and percutaneous wire fixation. Open reduction and wire fixation should be reserved for cases with signs of Volkmann's ischaemia, primary vascular or neural disruption, open fractures, and fractures with severe swelling not allowing acceptable reduction. Closed reduction and cast application is associated with a high risk of vascular impairment, may produce unacceptable results, and should be considered only in grade I fractures.

Acknowledgements. The authors greatly appreciate the excellent help of Miss Kamleh M. Rajab.

\section{References}

1. Flynn JC, Matthews JG, Benoit RL (1974) Blind pinning of displaced supracondylar fractures of the humerus in children. Sixteen years experience with long-term followup. J Bone Joint Surg [Br] 56:263-272

2. Haddad RJ Jr, Saer JK, Riordan DC (1970) Percutaneous pinning of displaced supracondylar fractures of the elbow in children. Clin Orthop 71:112-117

3. Liang LK (1970) A review of recent supracondylar fractures of the humerus in children. Singapore Med J 11:264

4. Mubarak SJ (1985) Ischemia from fractures and injuries about the elbow. In: Morrey BF (ed) The elbow. Saunders, Philadelphia, pp 289-301

5. Nacht JL, Ecker ML, Chung SMK, Lotke PA, Das M (1983) Supracondylar fractures of the humerus in children treated by closed reduction and percutaneous pinning. Clin Orthop 177:203-209

6. Piggot J, Graham HK, McCoy GF (1986) Supracondylar fractures of the humerus in children. Treatment by straight lateral traction. J Bone Joint Surg [Br] 68:577-583

7. Pirone AM, Graham HK, Rajbich JI (1988) Management of displaced extension-type supracondylar fractures of the humerus in children. J Bone Joint Surg [Am] 70:641-650

8. Siris IE (1939) Supracondylar fractures of the humerus. An analysis of 330 cases. Surg Gynecol Obstet 68:201

9. Smith L (1960) Deformity following supracondylar fractures of the humerus in children. J Bone Joint Surg [Am] 42:235-252

10. Swenson AL (1948) The treatment of supracondylar fractures of the humerus by Kirschner-wire transfixation. J Bone Joint Surg [Am] 30:993-997

11. Wadsworth TG (1982) The elbow. Churchill Livingstone, Edingburgh London Melbourne New York

12. Wallor A, Egund N, Eikelund L (1985) Supracondylar fracture of the humerus in children: review of closed and open reduction leading to a proposal for treatment. Injury 16:296-299

13. Weber BG, Brunner CH, Freuler F (1980) Treatment of fracture in children and adolescents. Springer, Berlin Heidelberg New York, pp 139-157

14. Worlock PH, Colton C (1987) Severely displaced supracondylar fractures of the humerus in children. A simple method of treatment. J Pediatr Orthop 7:49-53 